\title{
Elective advice
}

\author{
Shane O'Hanlon
}

\section{INTRODUCTION}

Going on a medical elective is an exciting opportunity. No matter where the destination, for most people it is an intensely rewarding experience, and the memories last a lifetime. However poor preparation can impinge on an otherwise productive elective, leading to lost opportunities. A little time spent considering your options will be time well spent.

\section{THINGS TO CONSIDER}

If this is your first time going on elective, you should talk to someone who already has some experience. Ask around your medical school or hospital. Ideally you should try to find someone who has already been to the hospital or project you are interested in.

Going in a group is easier than going alone. It can be an intense experience, and it is comforting to have someone you can relate to. It also helps when it comes to getting to know people when you arrive. Going it alone is the more challenging option, but can be a more interesting experience. Remember though that in remote areas in some countries it can be almost impossible to contact family and friends.

See if there are any local organizations which might provide sponsorship. Start your own volunteer group if you have the time. Choose a project which suits you, and do some research before you go. Many people decide to visit a developing country - it's not often that you have the chance to experience another culture while also providing benefits for the place you visit. Find travel information about the country, and get an idea of how the health system works there. Decide what skills you have to offer, and what time period you have free.

\section{ORGANIZING THE TRIP}

Make a shortlist of your preferred volunteer

*To whom correspondence should be addressed: Shane O'Hanlon 6 Cathedral Place, Bishop Street, Cork, Ireland

Email: sohanlon@gmail.com opportunities. Email or write the contact person, with any questions you have, and the dates you intend to go. Tell them how many are in your group, and what skills you can offer. If you are accepted in one placement, don't forget to let the others know you won't be coming. Once you have a confirmation, book your flights as soon as possible. If you are a student, try for student deals. For any obscure destinations, ask the contact person if they know which airlines fly there, or go to a specialized travel agent. As always the Internet is a good place to search for cheap airfares!

In the developing world, many hospitals are in financial difficulty, so any aid you can provide may literally be life-saving. Write to local businesses, medical organizations, or your local political representative for donations. Do not forget to hit up the other staff members in your local hospital/clinic who may have worked in the developing world in the past. Organize fund-raising events (coffee mornings, bagpacking, raffles, pub quizzes), and ask your local hospital if they have any equipment to spare. Bear in mind that some of the archaic stuff may not be suitable, while the stuff you think is useless may actually be a godsend... it is difficult to estimate this yourself but do make a serious effort to establish the level at which your hospital functions.

Pharmacies and GPs will also donate left-over or sample medications. You may receive some that are past sell-by date, but check with your contact person if these are useful. Unfortunately some hospitals charge patients even for donated drugs and this can be upsetting for volunteers who brought the drugs in good faith, not expecting them to be beyond their targeted patients' means... Again, check before you go.

Do not forget to see what the visa requirements are for your destination. Contact the embassy if you are unsure. Make copies of your passport, tickets, and other travel documents, and strongly consider travel insurance (if you're off to a remote destination check if you need extra cover in case you need the local flying 
doctors service, as this is not covered in many insurance policies).

Finally, try to plan some time at the end of your placement to relax, and see the local area.

\section{WHAT TO PACK}

Packing is an important consideration when planning your trip. Keeping your baggage weight to a minimum is vital, but you have to ensure to pack suitable clothes for the climate, and to bring work clothes too. Scrubs are essential - they are comfortable, cool in warm climates, and you can always leave them as a donation. Other essentials include: toiletries, basic medications, insect repellent, mosquito nets, washing powder, penknife, books...

Many volunteers bring useful medical equipment or medications, which are difficult to find locally. Unfortunately problems can be encountered at customs, so care should be taken. A letter from a head of your faculty, or other authority, stating that you are a volunteer with humanitarian supplies can help. Keep medications separate from other supplies, so that if they are confiscated you can keep the rest. An itemized list of everything you have is often required by the airlines. Also check if import tax must be paid on arrival - the embassy will advise you. Do not forget to ask for extra baggage allowance from the airline - they are usually very helpful, and this means more space for donations.

On the subject of books - a few compact ones are a great idea, especially if there is not much backup. They are also perfect as donations. Drug formularies are often requested, and other practical books like emergency manuals, or surgical atlases can be indispensable. Dental manuals and physiotherapy guides are also a possibility - check with your contact person to see what they need.

\section{PROBLEMS}

Once you get through customs, the next challenge is reaching your local destination. Transport is often far less comfortable and reliable than at home, but can be lots of fun! You may have to squeeze into packed minibuses with chickens on your lap, or negotiate at length with taxi-drivers for a reasonable fare. It can take hours to travel a few miles, so be patient.

Once you start work, it may not be what you expect. Remember you should try to fit in with the established schedules and practices, no matter how frustrating it might be! Always ask for help when in trouble, and if you have difficulties with staff members, talk it out. Stubbornness can be detrimental to patient care.

Living accommodations are usually very basic, and food may be a shock to the system. Remind yourself that you should try to adapt, and that it's not forever! A few home comforts, or high-energy food can help to ease the burden.

\section{SAFETY}

Always consider safety as your number one priority. While volunteers are usually welcomed everywhere, you may be targeted simply for being a foreigner. The worst time is usually on arrival, when you are getting orientated. Keep an eye on all your bags, and do not delay. You may receive many offers for help - politely refuse if you do not need it. For women, offers of marriage are common in some countries, but flashing a ring stops further solicitation! Take advice if you are a woman travelling alone.

Your safety while working is also important. If you are coming into contact with transmissible diseases, you should use preventive measures. Universal precautions are, as always, the rule. HIV prophylaxis packs are available, though costly. Note that policies regarding disposal of needles may not be the same as you are used to - be cautious and do not bring anything unwanted home with you. Your travel/health insurance may not cover you in this situation.

If you are going to a risky area, check the status before you go, and be aware of no-go areas. This information is usually available on government websites.

\section{CONCLUSION}

Going on an elective can be a once in a lifetime experience, so enjoy it! The vast majority of people come back relaxed, refreshed but also educated and fulfilled. If it works out, do not forget to pass on your tips!

Dr. Shane O'Hanlon (MB, BCh, BAO, BMedSci, MRCPI) is a specialist registrar in geriatric medicine at the Cork University Hospital in Ireland. As a student he went on electives to Africa, the Caribbean, France and Spain. This article gives some advice on how to go about organizing your elective, no matter what the destination. 